\title{
Obesity Effect on the Spine
}

\author{
Samir Zahaf1, Bensmaine Mansouri' ${ }^{1}$, Abderrahmane Belarbi1, Zitouni Azari² \\ ${ }^{1}$ Department of Mechanical Engineering, University of Sciences and Technology, Oran, Algeria \\ ${ }^{2}$ Laboratory of Biomechanics, Polymers and Structures, Ecole Nationale d'Ingénieurs de Metz, Metz, France \\ Email: zahafsamir1983@gmail.com, Smail_Mansouri@yahoo.fr, Belarbi_abd@yahoo.fr, azari@univ-metz.fr
}

Received 17 May 2015; accepted 21 August 2015; published 24 August 2015

Copyright (C) 2015 by authors and Scientific Research Publishing Inc.

This work is licensed under the Creative Commons Attribution International License (CC BY). http://creativecommons.org/licenses/by/4.0/

(c) (i) Open Access

\begin{abstract}
The objective of this work is to study the effect of obesity on the intervertebral discs and provide system analysis of the spine between multiple configurations of people, and know the risks due to this eccentric load (Big Belly). The results show that in all three previous loadings (obese people), the distributions of stress and strain are high in both D1 and D10 intervertebral discs. This shows that the distance between the point of load application and the spine axis has an important role in solicitation increasing and therefore its deformation: as main conclusion is that the concentration of the mass of stomach fat is a risk factor that leads to pain problems, deformation and herniated disc.
\end{abstract}

\section{Keywords}

Obes, Lumbar-Thoracic, Intervertebral Discs, Finite Element, Biomechanics, Von Mises Stress-Strain, Disc Degeneration

\section{Introduction}

The prediction of the mechanical behavior of the spine system is one of the major problems of biomechanics [1]. A better understanding of moving mechanisms of spine under different loads and stress distribution in this system is of fundamental importance in the advancement of technologies in the areas of spinal restorations inter vertebral prostheses, and osteopathic medicine bone [2].

The spine or rachis consists of a movable column of 24 free vertebrae and a fixed column formed of fused vertebrae: the sacrum and coccyx (Figure 1); it is the fixing strut of many essential muscles in the posture and locomotion and protects the spinal cord located in the vertebral canal; it supports the head and transmits the weight of the body to the hip joints; with a length of about $70 \mathrm{~cm}$ in men (60 $\mathrm{cm}$ in women), its reduction may reach $2 \mathrm{~cm}$ when standing [3].

The degeneration of the lumbar discs is definitely related to BMI; overweight and obesity are associated with a higher risk of problems of the spine. The MRI study [4] published in the January 30 edition of Arthritis and 


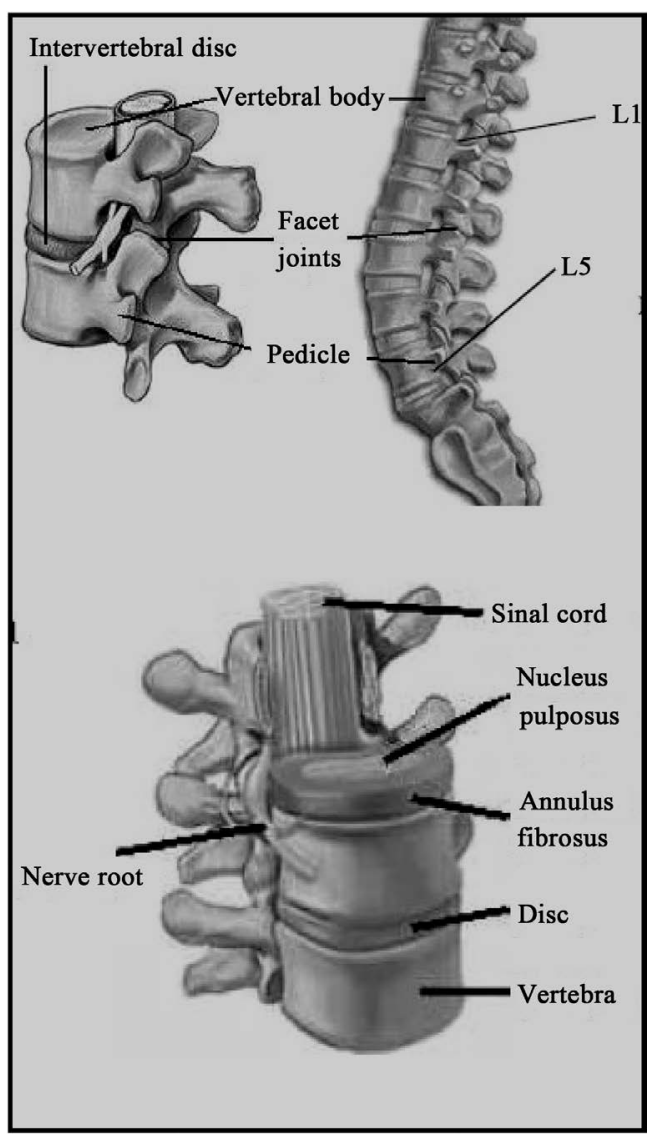

Figure 1. Anatomy of the lumbar spine [5].

Rheumatism, the Journal of the American College of Rheumatology, alerts on this effect of overweight in the development of degenerative disc disease and back pain and then herniated disc (Figure 3).

The term obesity is defined as an eccentric load (Figure 2); the load is represented by the mass of the belly (P1). In this work, the simulations of the disc degeneration, based on a finite element model of the spine depending on the mechanical properties were established; to define the boundary condition restriction on movements of translation and rotation of the spine has been applied in the frontal plane. We propose in this work to draw up a comprehensive study of stresses and deformations in the spinal discs distributions based on supported loads. The results showed that the level of degeneration increased in all inters vertebral discs but concentrated in the two disks D1 and D10.

Figure 3 shows two vertebrae of the spinal column with an intervertebral disc under the effect of a compound loading (compression $\mathrm{P}+$ bending moment $\mathrm{P} 1$ ). The compressive load $\mathrm{P}$ creates an internal pressure in the nucleus. This pressure will there after generate the disc degeneration or degenerative disc disease (Figure 4). As regards the forward flexion P1, if the load of the stomach increases, automatically distance between the point of load application and the axis of the spinal column increases, we see that the posterior portion of the annulus fibrosis is tensioned and the other front portion is compressed, that is to say the nucleus pulposus burst back (posterior compression), and this compression produced by disc protrusion comes into contact with a nerve root called herniated disc.

\section{Material and Methods}

The objective of this work is to provide an analysis between a geometric configuration of the spine system, to find the effect of eccentric loads on the latter and mainly on the inter vertebral discs by analyzing the stress distribution in this system using a 3D numerical simulation, based on the principles of the finite element method. The analysis of biomechanical problems includes several steps. 


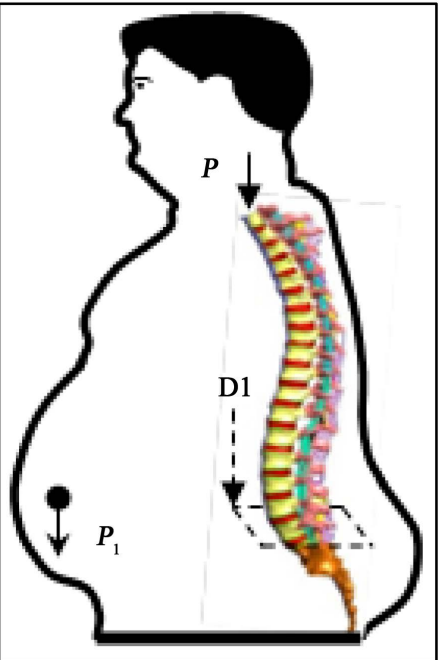

Figure 2. Constitution spine (obese person) at the disc depending on its condition.

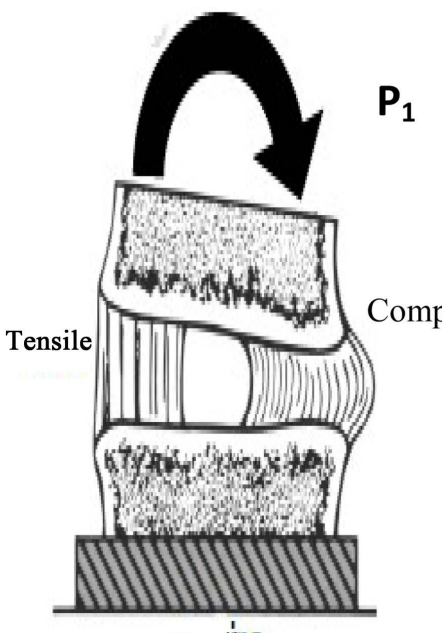

Bending

(a)

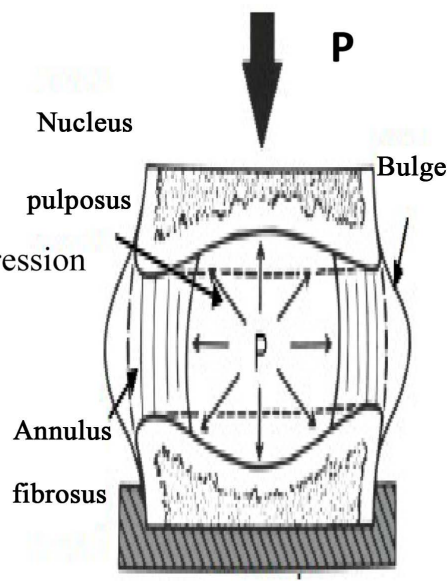

Compression

(b)

Figure 3. The intervertebral disc with (a) compression (b) bending [6].

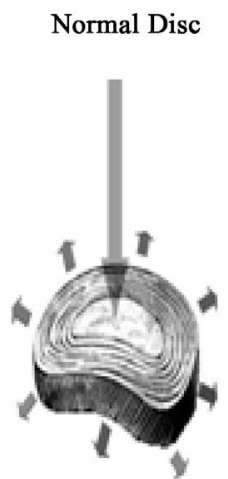

$\mathrm{D}_{1}$

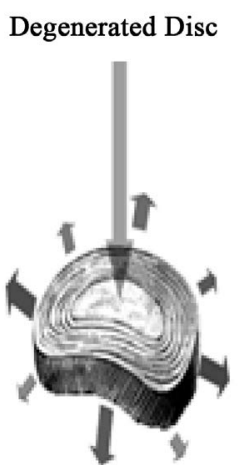

$\mathrm{D}_{1}$
Herniated disc

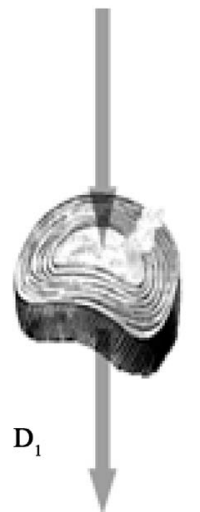

Figure 4. Load distribution at the disc D1 according to his [7] state. 
The first is to study the form to define the geometrical configuration of the object, which allows the reconstitution of the vertebra, the ligament and bone using CAD programs.

The result is a 3D geometric model including these three components will then be prepared for use in finite element analyzes for the study of stresses and deformations distribution in the system.

The Steps to the execution of the 3D vertebra model (Figure 5).

a) Draw cortical bone that is the upper hinge and the lower hinge, and make the smoothing; this gives a solid body called the vertebral body.

b) Secondly, draw the posterior arch (blade + the pedicle) with the spinousprocess.

c) Finally we draw the transverse process.

The simulation of the disc degeneration is based on a finite element model of the healthy spine. Figure 6 shows a spine model, this consists of five lumbar vertebrae (L1, L2, L3, L4 and L5) plus the sacrum, twelve thoracic vertebrae (TH1, TH2, TH3, TH4, TH5, TH6, TH7, TH8, TH9, TH10, TH11, TH12) and 17 inter vertebral discs between (S1-L5, L5-L4, L4-L3, L3-L2, L2-L1, L1-TH12 TH12-TH11, TH11, TH10, TH10-TH9, TH9-TH8, TH8-TH7, TH7-TH6, TH6-TH5, TH5-TH4, TH3-TH4, TH3-TH2 TH2-TH1) and various ligaments thoracic lumbar spine (anterior longitudinal ligament, posterior longitudinal ligament, ligament interspinous ligament supraspinatus, yellow ligament and capsular ligament).

In static loading conditions, the model of the reconstructed spine is used in an analysis for studying the role of the inter vertebral discs and the stress distribution in these disks as well as its supporting structures. The spine is reconstructed in 3D to study the system dimensions (IVD-ligament-bone) (Figure 7).

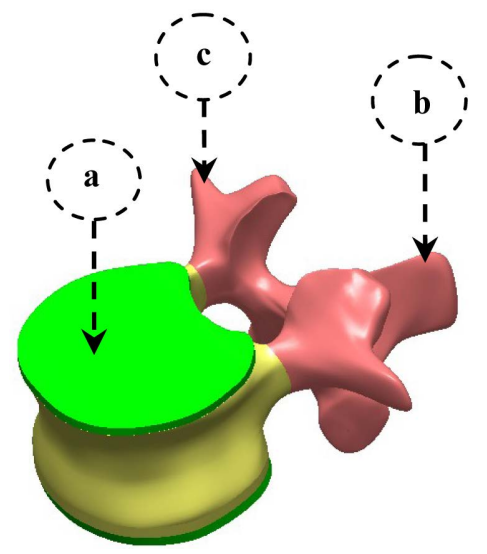

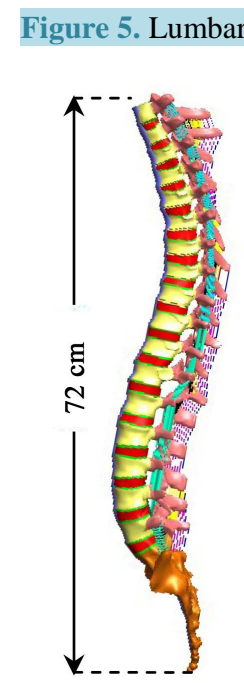

(a)

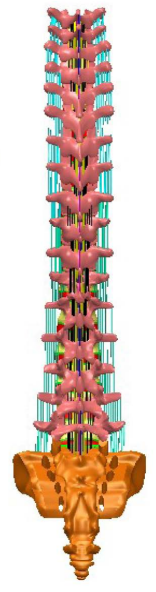

(b)

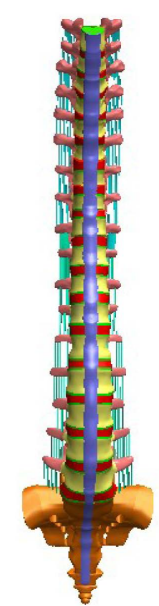

(c)

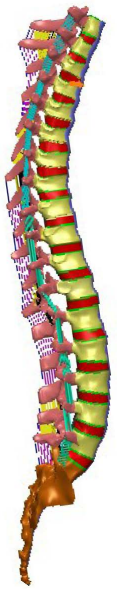

(d)

Figure 6. Spine studied. (a) Lateral (left) view; (b) Dorsal view; (c) Front view; (d) Lateral (right) view. 

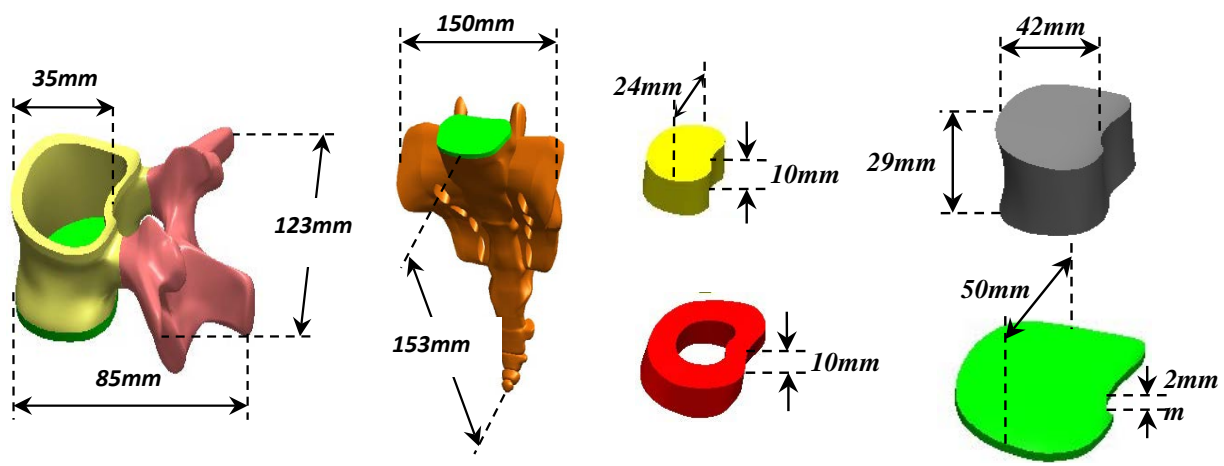

Figure 7. Vertebra and sacrum dimensions.

In order to define the boundary conditions, restriction on movements of translation and rotation of the spine has been applied in the lower plane, and defined as having zero displacements. Several charges in the anterior direction were applied as follows:

- The application of the load on the upper side of the thoracic vertebra TH1.

- The fixed part applied to the body of the sacrum.

- The interfaces between the different components of the system of the spine, the cortical bone, the inter vertebral disk and ligament are treated as perfectly bonded interfaces (Figure 8).

Figure 9 shows an isometric view of an exploded assembly of the spine and each component of the spine system is denoted by letters.

The selection of constitutive equations of the vertebral bone is defined as the part of the bone which carries the inter vertebral disc, composed of cortical bone, cancellous bone, the posterior arch, with a Young's modulus of about 12,000 MPa. It is recognized that cortical bone: has: better load capacity than the cancellous bone: cortical bone is considered as an isotropic material, and homogeneous linear elastic.

Table 1 shows the tensile strength of the structure annulus fibrosis different authors. These materials are in herently anisotropic and non-linear elastic.

The behavior of intertransverse ligament and inter-spinous ligament is nonlinear viscoelastic as in previous studies [8]; a linear elastic model is chosen to represent this behavior.

ANSYS WORKBENCH software was used for analyzing this geometry and generate the most suitable mesh. For the studied behavior, we used tetrahedral elements, type Solid187 conforming to defined parametric surfaces (Figure 10). It is necessary to mesh the components of the spine with small and confused elements to ensure optimum accuracy of the results of stresses and strains in the inter vertebral discs.

The material properties of the spine components were selected after a careful review of the published literature (Table 2) it was considered appropriate to define the cortical and cancellous bone as homogeneous and isotropic. The magnitudes of 12,000 MPa and $100 \mathrm{MPa}$ (cortical and cancellous, respectively) were observed in all studies by various researchers. Since physiologically the nucleus is fluid filled, the elements were assigned low stiffness (1 MPa) values and near incompressibility properties (Poisson's ratio of 0.499). Biologically, the annulus fibrosus is comprised of layers of collagen fibers, which attributes to its non-homogenous characteristics. However, due to limitations in modeling abilities, the annulus was defined as a homogenous structure with a magnitude of 4.2 MPa. This was based on the modulus of the ground substance (4.2 MPa) and the collagen fibers reported in the literature, taking into account the volume fraction of each component.

The complete model of the spine (Figure 10) was realized by the SOLIDWORKS SOFTWARE VERSION 2014 and was then transferred to the software Calculates each element ends ANSYS 14.5 WORKBENCHE generated the default mesh then generated linear global custom mesh tetrahedra 10 nodes conform to surface.

The result ends element models of the spine contain a condensed mesh (Figure 10).

Figure 10 shows a complete model that consists of 11,762,783 elements and 17,150,901 nodes. L'os cortical contains (3,585,646 element and 5,132,199 nodes), cancellous bone in the cortical bone contains $(2,496,448$ element $3,471,929$ nodes).

The posterior arch was modeled with tetrahedral elements to 10 nodes contains (2,377,091 element, 3,440,842 nodes), the nucleus pulposus in the annulus fibrosus were modeled with tetrahedral type elements 10 nodes (504,657 element 717,205 nodes), the annulus fibrosus were modeled with elements of type tetrahedral to 10 


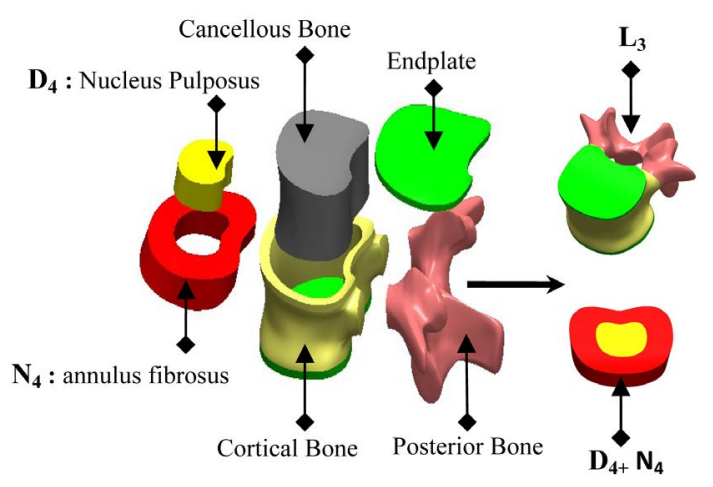

Figure 8. 3D modeling thoracic vertebra L3, D4 disc of the lumbar spine (SOLIDWORKS 2014 software).
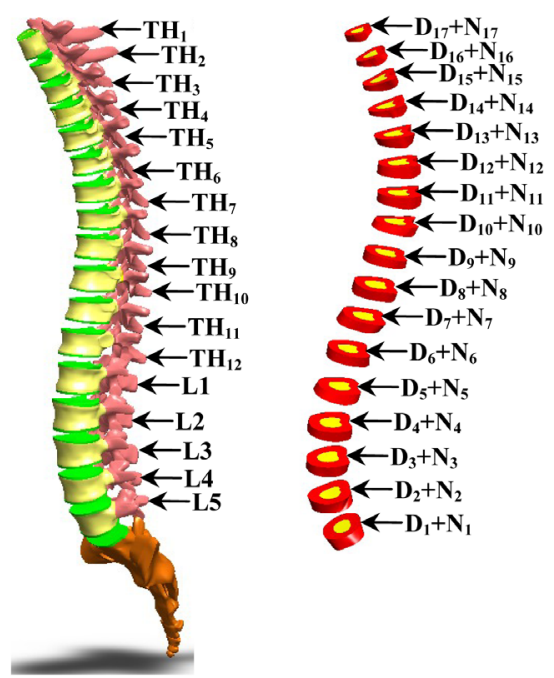

Figure 9. Assemblies in isometric perspective. Abbreviations: $D_{1}$ : intervertebral disk upstairs one; $\mathrm{N}_{1}$ : nucleus in the intervertebral disc upstairs one; $\mathrm{D}_{10}$ : intervertebral disk upstairs ten; $\mathrm{N}_{10}$ : nucleus in the intervertebral disc upstairs ten; $\mathrm{L}_{4}$ : lumbar vertebra is on level four; $\mathrm{D}_{4}$ : intervertebral disk upstairs four; $\mathrm{N}_{4}$ : nucleus in the intervertebral disc upstairs four; MRI: Magnetic resonance imaging; FEM: Finite Element Method; IVD: inter vertebral disc.
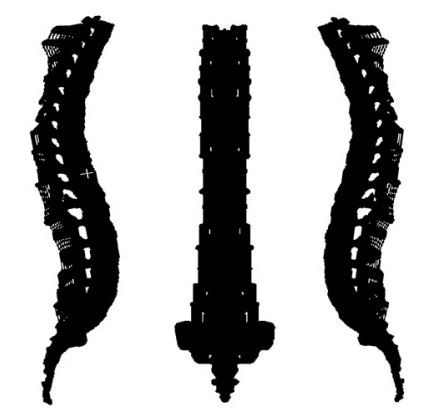

Figure 10. Spine 3D finite element modeling (Ansys14.5 software).

Table 1. Mechanical characteristics of disc tissue [9].

\begin{tabular}{cc}
\hline Authors & $\boldsymbol{\sigma r}\left(\mathbf{N} / \mathbf{m m}^{\mathbf{2}}\right)$ \\
\hline BROWN (axiale) & 1.4 \\
GALANTE (horizontale) & $3.5 \pm 0.3$ \\
GALANTE (sens fibre) & $10.7 \pm 0.9$ \\
WU & 3.7 \\
\hline
\end{tabular}


Table 2. Material properties specified in the model.

\begin{tabular}{cccc}
\hline Material & $\begin{array}{c}\text { Young modulus } \\
\text { (MPa) }\end{array}$ & $\begin{array}{c}\text { Poisson } \\
\text { coefficient }\end{array}$ & References \\
\hline Cortical bone & 12,000 & 0.3 & {$[10]-[21][26][35][37]-[40][42][43]$} \\
Cancellous bone & 100 & 0.2 & [10] [13] [14] [16]-[18] [20] [21] [23]-[26] [35] [37]-[40] [42] [43] \\
Posterior bone & 3500 & 0.25 & {$[12]-[14][17][18][20][21][23][26][27][36]-[39]$} \\
Cartilage endplates & 12,000 & 0.3 & [20] [22] [24] [28] \\
Annulus ground substance & 4.2 & 0.45 & [10] [13] [16] [18]-[22] [24] [26] [30] [31] [34]-[39] [42] [43] \\
Nucleus pulposus & 1 & 0.499 & [11] [13]-[15] [17] [19] [20] [26] [29] [32]-[38] [42] [43] \\
Anterior longitudinal ligament & 20 & 0.3 & {$[13][14][16]-[18][36][37][40][41]$} \\
Posterior longitudinal ligament & 20 & 0.3 & {$[13][14][16][17][36][37][40][41]$} \\
Ligamentum flavum & 19.50 & 0.3 & {$[13][14][16][17][36][37][40][41]$} \\
Intertransverse ligament & 58.7 & 0.3 & {$[13][14][16][17][36][37][40][41]$} \\
Inter-spinous ligament & 11.6 & 0.3 & {$[13][14][16][17][36][37][40][41]$} \\
Supra-spinous ligament & 15 & 0.3 & {$[13][14][16][17][36][37][40][41]$} \\
Capsular ligament & 32.9 & 0.3 & {$[13][14][16][17][36][37][40][41]$} \\
\hline
\end{tabular}

nodes (1,434,546 element , 2,059,247 nodes). The gelatinous cartilage modeled with a tetrahedral element to 10 nodes (912,759 elements, 1,431,242 nodes). Finally the different types of ligaments generated by a tetrahedral mesh to 10 nodes (Table 3 ).

The diagram in (Figure 11) shows a normal person standing with a specific weight of $80 \mathrm{~kg}$, the total mass (belly) is $13.25 \mathrm{~kg}$ representing the weight $\mathrm{P} 1$; the pressure load $\mathrm{P}$ is the mass of the top portion of the person's body (hands, forearms, arms, head) divided by the area of the thoracic vertebra TH1.

The length of the spine (thoracic + lumbar) is $72 \mathrm{~cm}$ and the distance between the specific weights of the belly which is the point of application of the load and the axis of the vertebral column $(20 \mathrm{~cm})$. For boundary conditions, the sacrum is fixed. (Embedding the sacrum (Figure 12).

We propose in this section to draw up a detailed study of Von Mises distributions constraints and deformations in the intervertebral discs as a function of supported loads.

Figure 12 shows three people in standing position, with respective specific bellies weight P1 (16.56 Kg, $19.88 \mathrm{~kg}, 24.85 \mathrm{~kg})$.

The distance between the center of gravity of the belly and the axis of the vertebral column is between (30 $\mathrm{cm} / 50 \mathrm{~cm}$ ), the pressure load $\mathrm{P}$ is applied on the thoracic vertebra TH1.

To define the boundary conditions, restriction on movements of translation and rotation of the spine has been applied including frontal plane and defined as having zero displacements on the sacrum see Figure 12.

Consider the example of an anterior load (obese person), the colors represent the Von Mises stresses experienced by 17 intervertebral discs, blue represents the minimum stress and the red represents the maximum stress.

\section{Results}

Figure 13 shows clearly that the anterior load affects the disk D1 and D10 is the two most sought discs compared to other drives in the thoracic lumbar spine.

A load applied to the upper surface of the TH1 thoracic vertebra of the spinal column causes a high concentration of maximum Von Mises stresses in the anterior portion of the two discs D1 and D10 (red section) this is mentioned in Figure 14.

Moreover, the Von Mises stresses are minimal at the posterior part of the two intervertebral discs D1, D10 (blue contour) see Figure 14.

Figure 15 shows the Von Mises strain histogram in the inter vertebral discs for a normal person load $13.25 \mathrm{~kg}$. We note that the Von Mises deformation values are highest in the two discs D1, D10 $(2784,2377)$ outline in red; this is mentioned in Figure 16. 

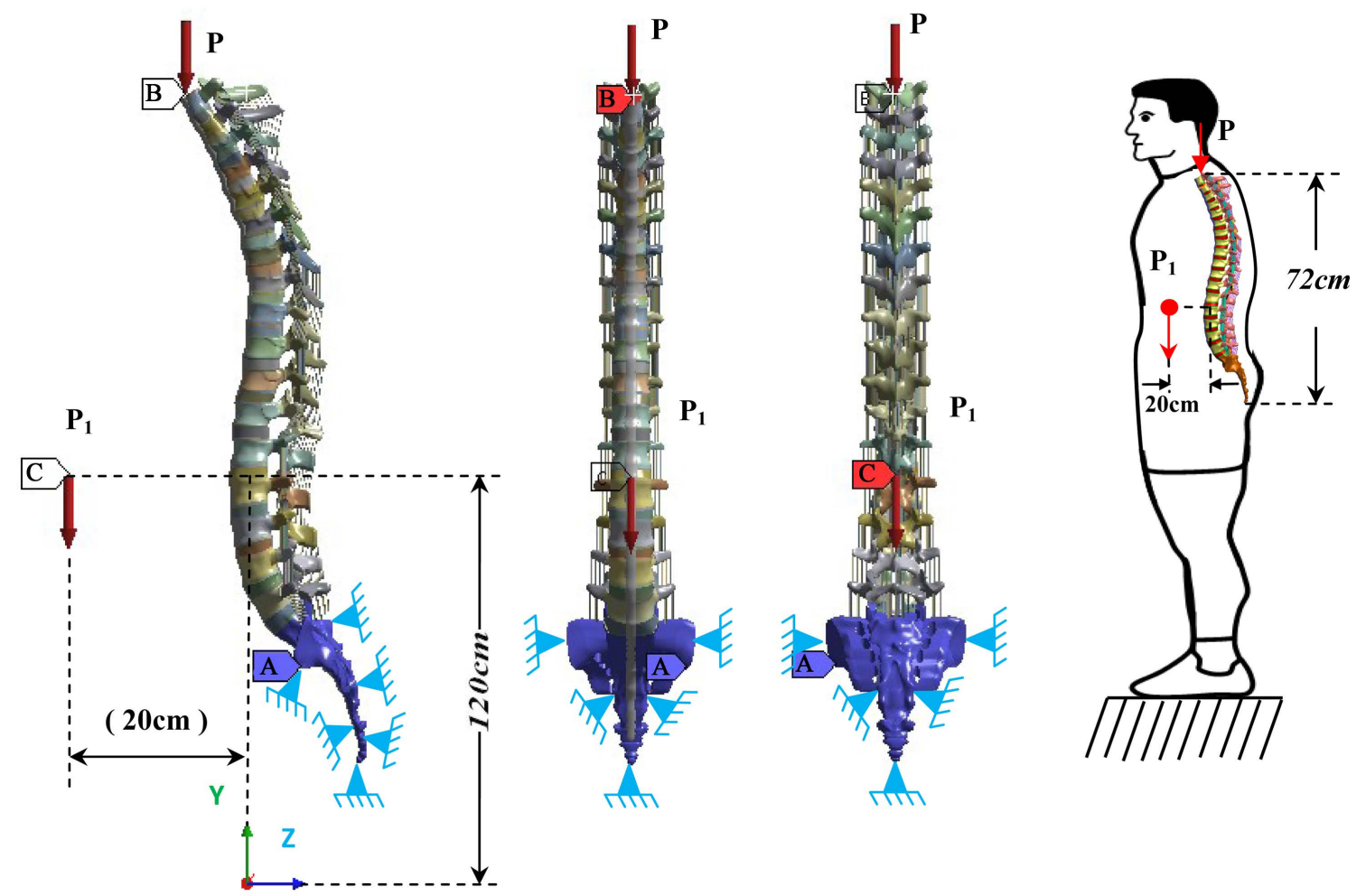

A Fixed support. $\mathrm{B}$ Pressure $: \mathbf{P}=\mathbf{1 . 0 1}$ MPa. $\mathrm{C}$ Distant load $: \mathbf{P}_{\mathbf{1}}=\mathbf{1 3 2 . 5}$.

Figure 11. Mechanical model of the spine anterior load (normal person).

Table 3. Element and node numbers in the column vertebral system components.

\begin{tabular}{cccc}
\hline Component & Nodes & Elements & Thickness \\
\hline Cortical bone & $5,132,199$ & $3,585,646$ & $1 \mathrm{~mm}$ \\
Cancellous bone & $3,471,929$ & $2,496,448$ & $1 \mathrm{~mm}$ \\
Posterior bone & $3,440,842$ & $2,377,091$ & $1 \mathrm{~mm}$ \\
Cartilage endplates & $1,431,242$ & 912,759 & $1 \mathrm{~mm}$ \\
Annulus ground substance & $2,059,247$ & $1,434,546$ & $1 \mathrm{~mm}$ \\
Nucleus pulposus & 717,205 & 504,657 & $1 \mathrm{~mm}$ \\
Anterior longitudinal ligament & 227,078 & 128,365 & $1 \mathrm{~mm}$ \\
Posterior longitudinal ligament & 158,748 & 92,426 & $1 \mathrm{~mm}$ \\
Ligamentum flavum & 30,226 & 13,447 & $1 \mathrm{~mm}$ \\
Transverse ligament & 285,328 & 131,648 & $1 \mathrm{~mm}$ \\
Inter-spinous ligament & 28,968 & 13,158 & $1 \mathrm{~mm}$ \\
Supra-spinous ligament & 17,833 & 8279 & $1 \mathrm{~mm}$
\end{tabular}



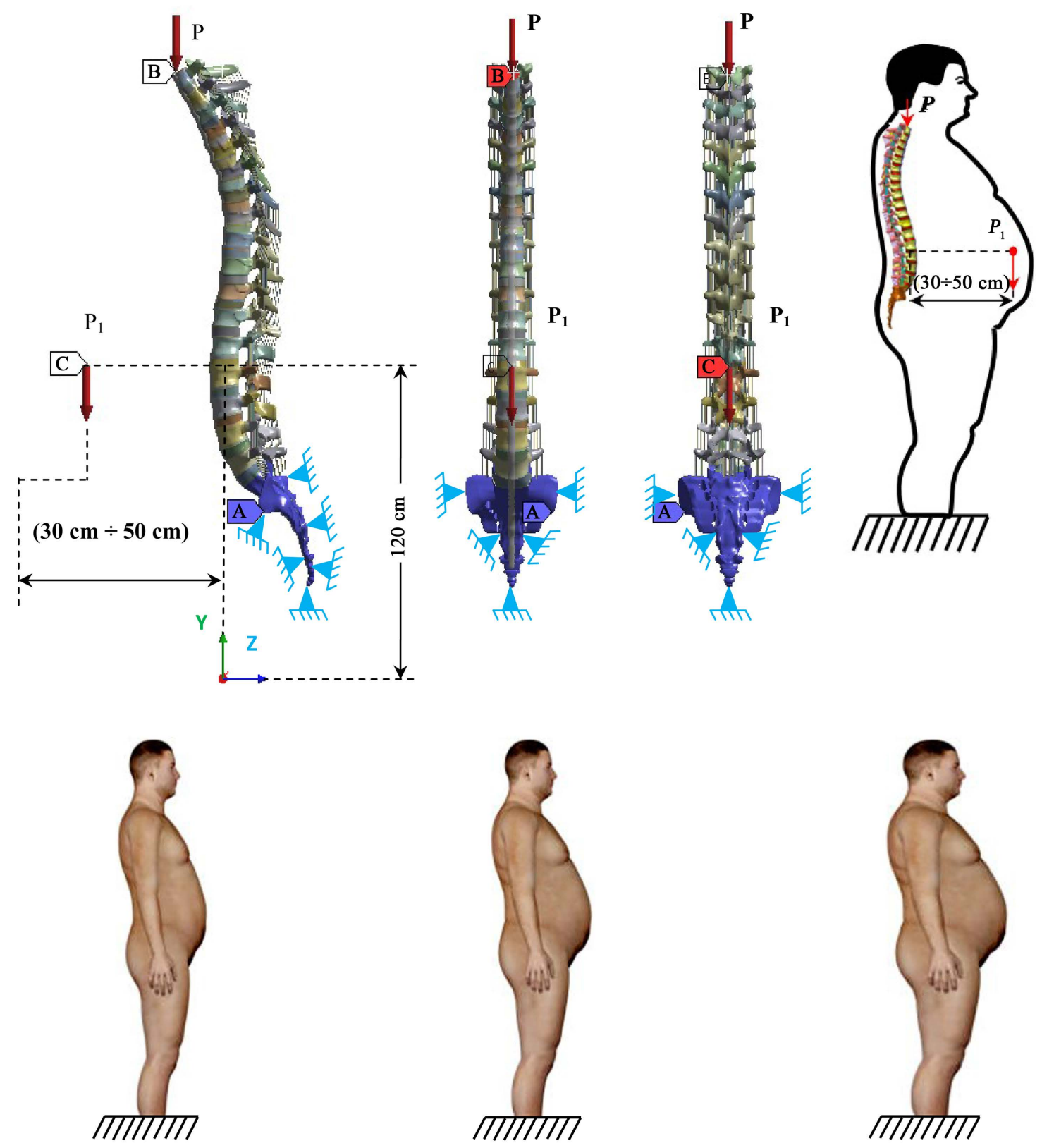

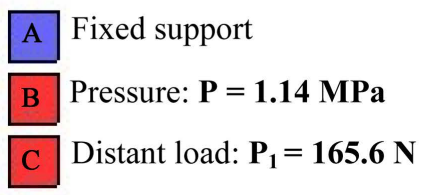

(a)

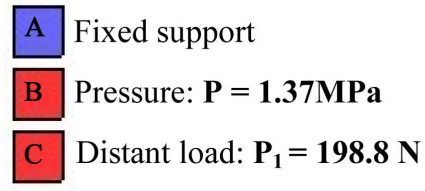

(b)
A Fixed support
B Pressure: $\mathbf{P}=\mathbf{1 . 7 2} \mathrm{MPa}$
C Distant load: $\mathbf{P}_{\mathbf{1}}=\mathbf{2 4 8 . 5} \mathbf{N}$

(c)

Figure 12. Mechanical model of the spine [anterior load (fat person)].

Consider the example of an anterior load (obese person), the colors represent the Von Mises stresses experienced by 17 intervertebral discs, blue represents the minimum stress and the red represents the maximum stress. Figure 17 shows the role of the intervertebral discs in the stress absorbing. Their distribution in the spine tends to be concentrated in the disc D1 on both sides, for the front side, a tracted portion to a maximum value of 15.216 MPa and the other has a minimum value of 0.035 MPa (Figure 18). 


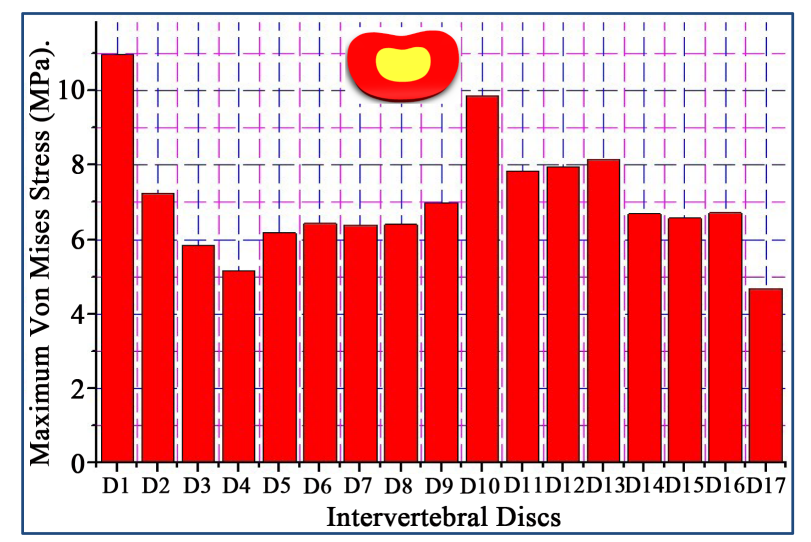

Figure 13. Histogram of the Von Mises stress in the IVD for a load of $13.25 \mathrm{~kg}$.

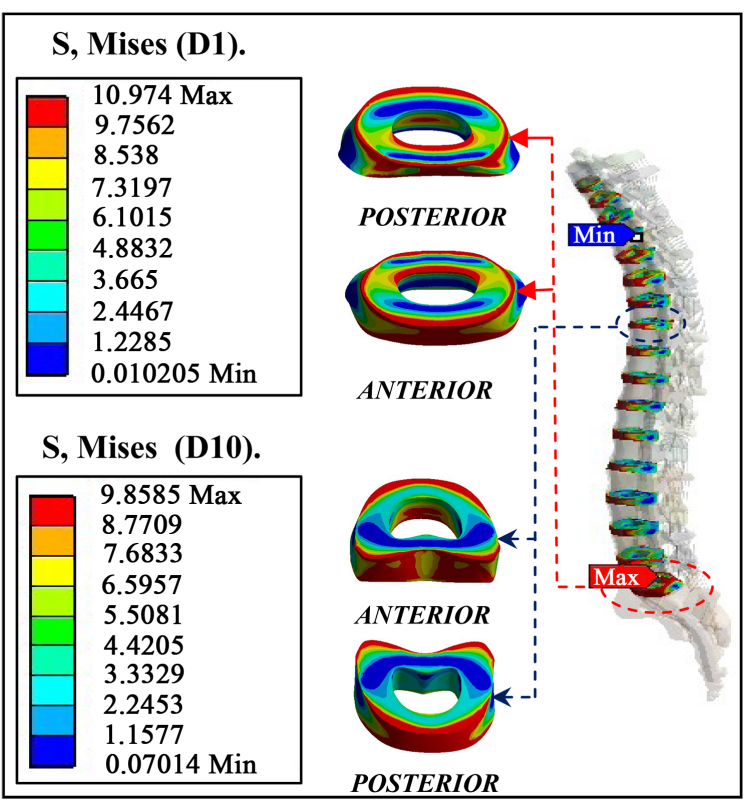

Figure 14. Von Mises stresses Distribution in the discs D1 and D10 for a load of $13.25 \mathrm{~kg}$.

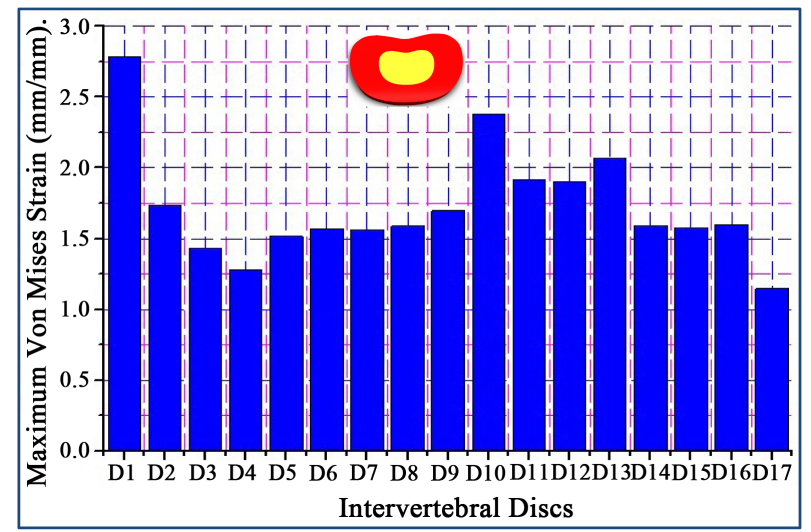

Figure 15. Histogram of the Von Mises strains in the IVD for a load of $13.25 \mathrm{~kg}$. 


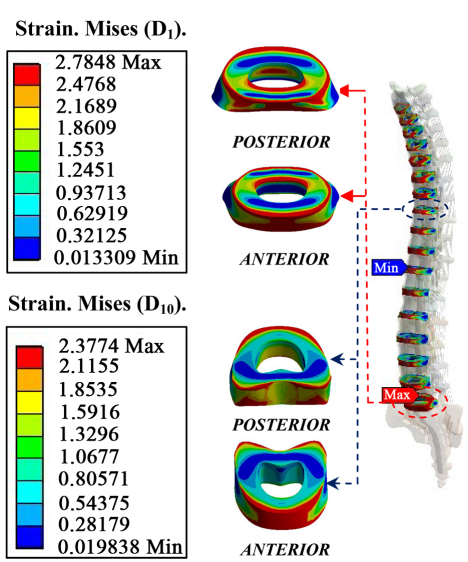

Figure 16. Von Mises strains Distribution in the discs D1 and D10 for a load of $13.25 \mathrm{~kg}$.
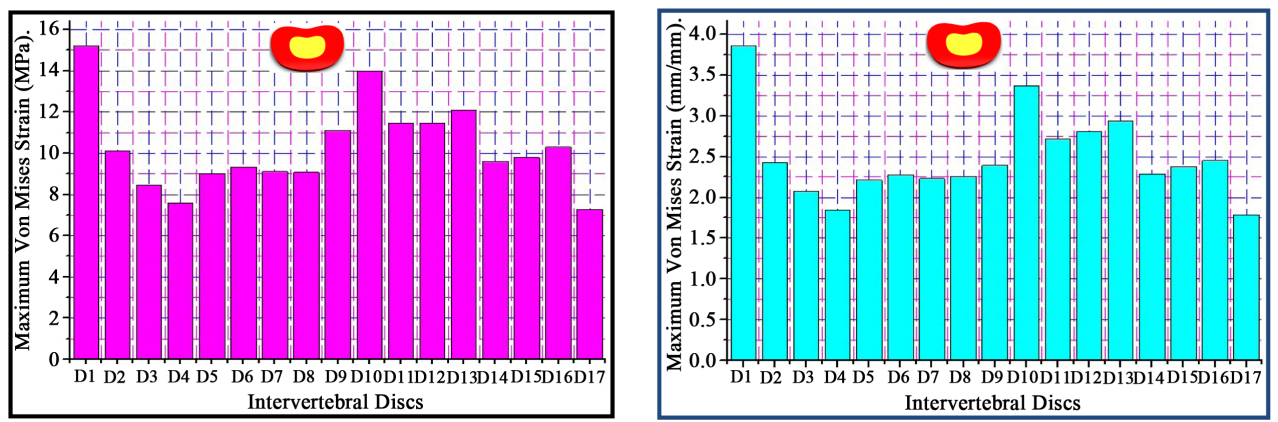

(a)
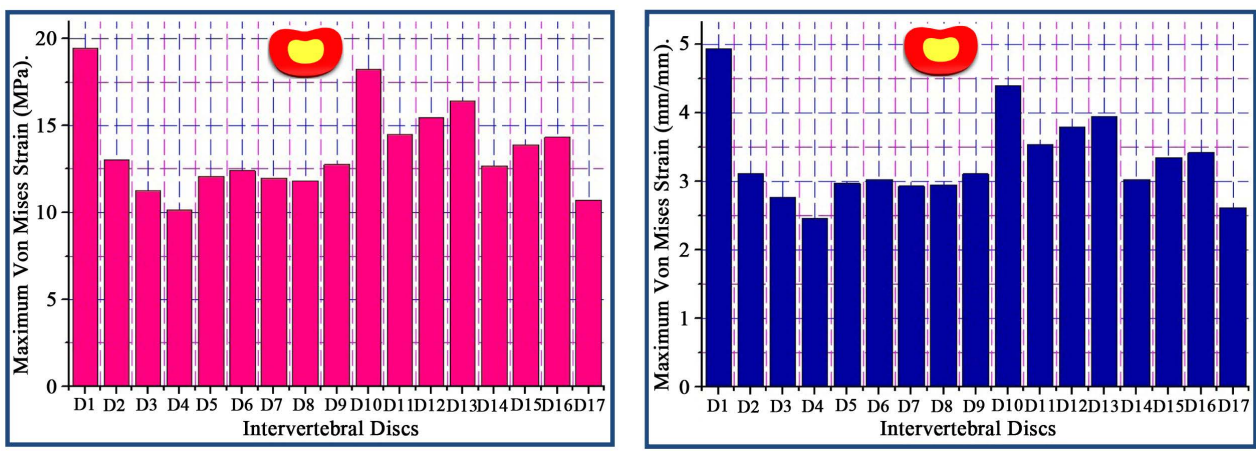

(b)
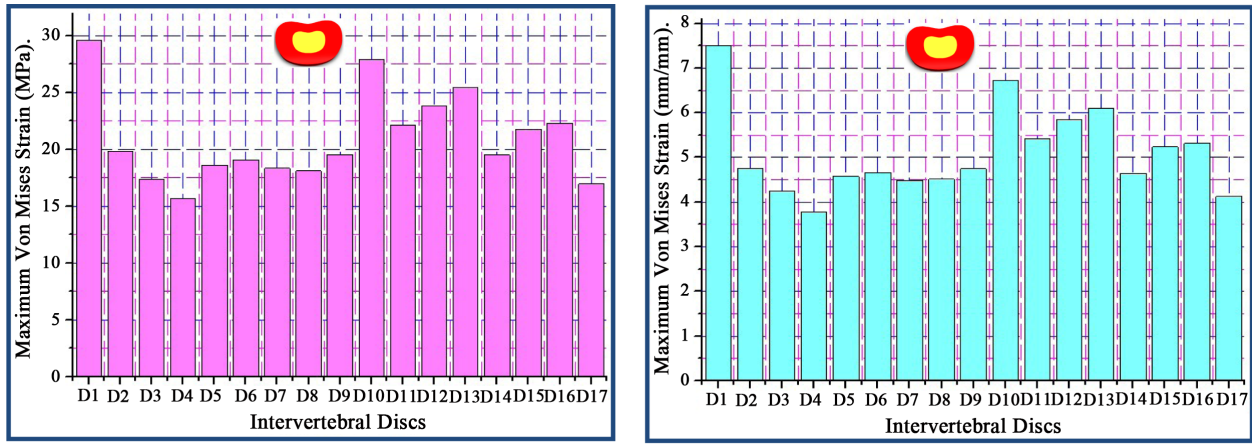

(c)

Figure 17. Histogram of the Von Mises stress and strains in the IVD for a Diffrent load. (a) $16.56 \mathrm{~kg}$; (b) $19.88 \mathrm{~kg}$; (c) $24.85 \mathrm{~kg}$. 

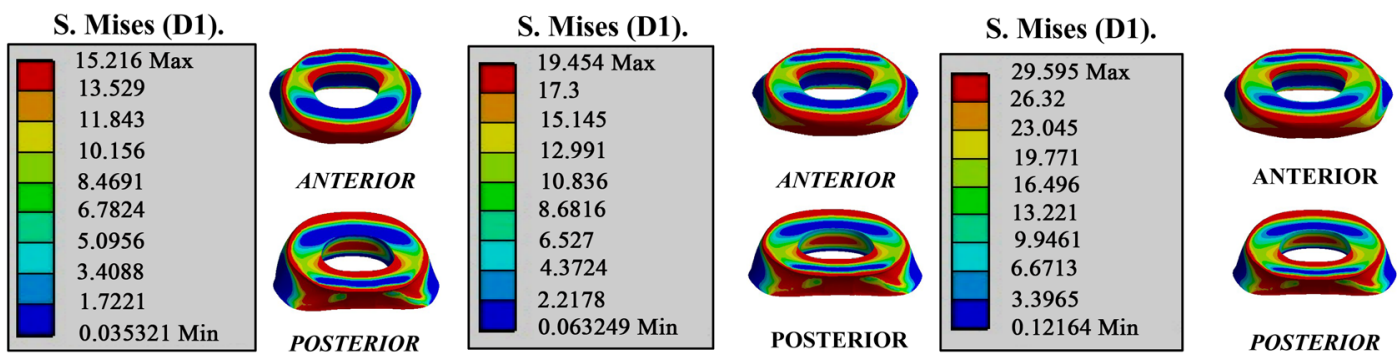

ANTERIOR

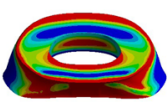

POSTERIOR

S. Mises (D10).

\begin{tabular}{||l|}
\hline 13.969 Max \\
12.429 \\
10.888 \\
9.3481 \\
7.8078 \\
6.2675 \\
4.7271 \\
3.1868 \\
1.6464 \\
0.10609 Min \\
\hline
\end{tabular}

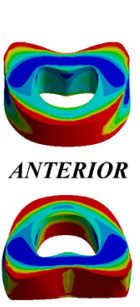

S. Mises (D10).

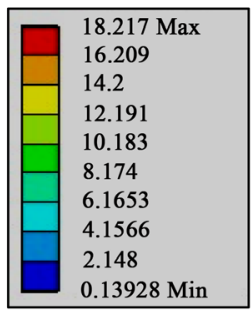

S. Mises (D10).

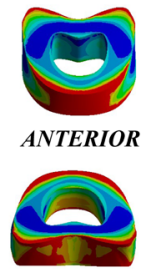

POSTERIOR

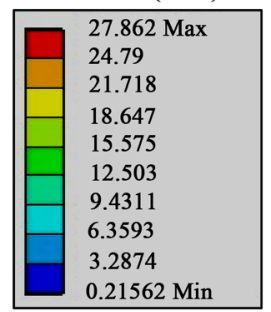

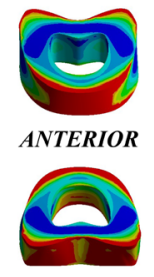

POSTERIOR

POSTERIOR

Strain. Mises (D1).
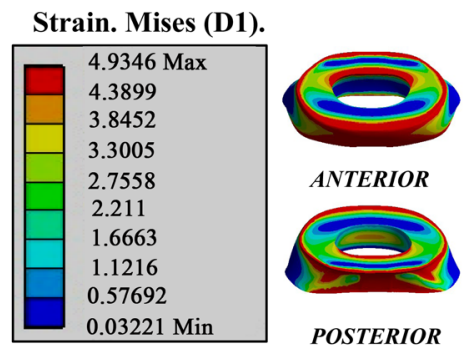

POSTERIOR
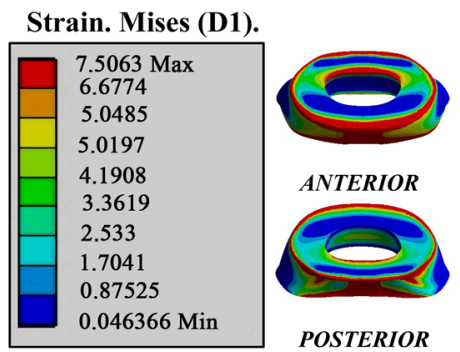

Strain. Mises (D10).

Strain. Mises (D10).

\begin{tabular}{|l|l|}
\hline & 4.3931 Max \\
3.9088 \\
3.4246 \\
2.9403 \\
2.4561 \\
1.9718 \\
1.4876 \\
1.0033 \\
0.51909 \\
0.034838 Min \\
\hline
\end{tabular}



(b)


ANTERIOR

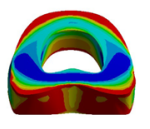

(c)

Figure 18. Histogram of the Von Mises stress and strains in the IVD for a Diffrent load. (a) $16.56 \mathrm{~kg}$; (b) 19.88 kg; (c) $24.85 \mathrm{~kg}$.

\section{Discussion}

We see in Figure 18 and Figure 19 Von Mises stresses reached a maximum value concentrated in the two discs D1, D10 which are equal to 15.21 MPa, 13.96 MPa for the first person, 19.454 MPa, 18.217 MPa for the second person and 29.595 MPa, 27.862 MPa for the third person who is located in the anterior portion of the disc (red part).

Regarding the deformations Von Mises, we notice that the values are greatest in the two intervertebral discs D1, D10 of 3.86, 3.788 for a load of $16.55 \mathrm{~kg}$ obesity and 4.934, 4.393 for an obesity load $19.88 \mathrm{~kg}$ and 7.506, 6.718 for an obesity load $29.85 \mathrm{~kg}$ compared to other discs of the vertebral column (Figure 18). Finally a nor- 
mal person (without obesity), Von Mises stresses are concentrated in both discs D1 and D10 with values of 10.974 MPa, 9.858 MPa see Figure 14. In the case where the obesity of load augment that is to say the distance between the load application point and the axis of the spine augment (the most risky cases). These loads will cause according to the maximum distance of major constraints that will generated a phenomenon called disc degeneration (herniated disc) posterior side of the disc from its side will overwrite the spinal nerve (spinal cord) see Figure 20(a) and Figure 20(b).

\section{Conclusions}

In sum, we concluded for the three cases of anterior load (obese persons) (Figure 19), that the distributions of
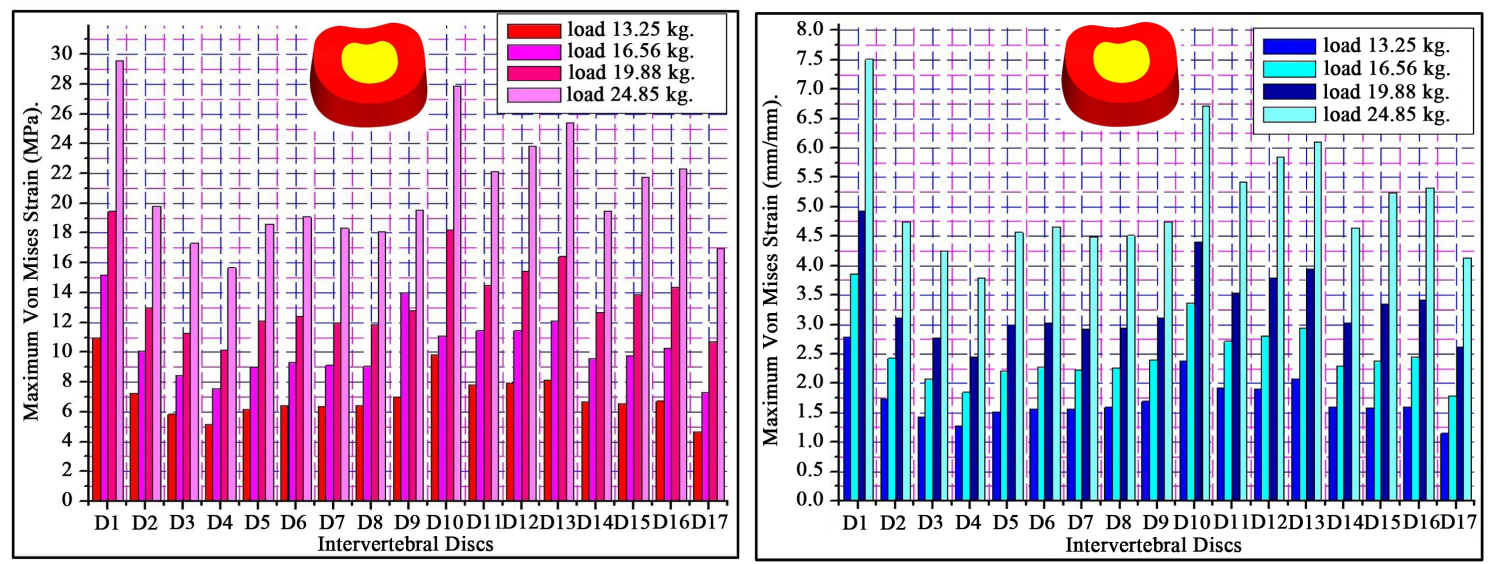

Figure 19. Histogram of the Von Mises stress and strains in the IVD for a Different loads.

Strain. Mises (D1).

\begin{tabular}{|l|l|}
\hline & $7.5063 \mathrm{Max}$ \\
6.6774 \\
5.8485 \\
5.0197 \\
4.1908 \\
3.3619 \\
2.533 \\
1.7041 \\
0.87525 \\
$0.046366 \mathrm{Min}$ \\
\hline
\end{tabular}

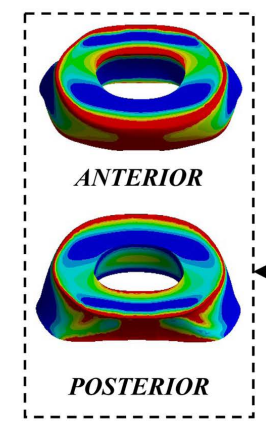

S. Mises (D1).

\begin{tabular}{|l|}
\hline 29.595 Max \\
26.312 \\
23.029 \\
19.746 \\
16.463 \\
13.18 \\
9.8976 \\
6.6147 \\
3.3318 \\
$0.048896 \mathrm{Min}$ \\
\hline
\end{tabular}
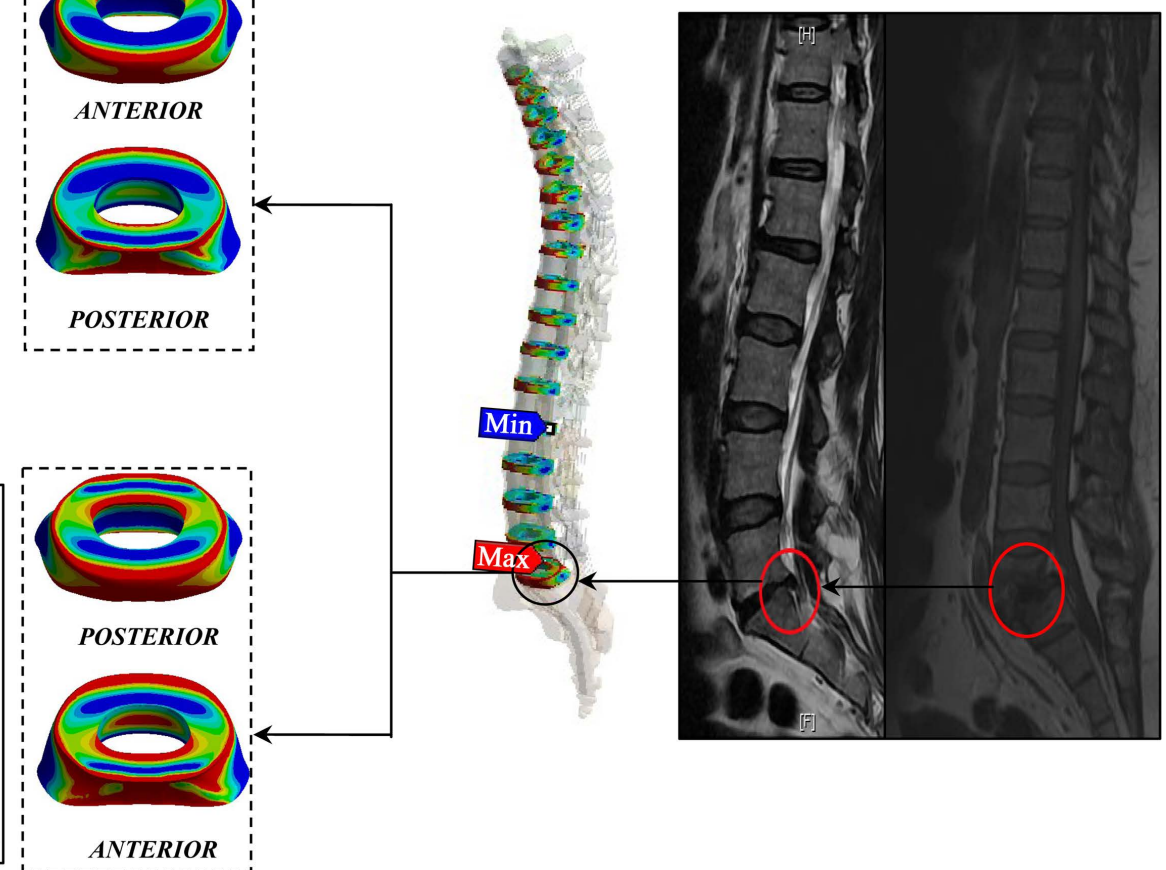

(a)

(b)

Figure 20. (a) Distribution of the Von Mises stress and strains in the Discs D1 for load 24.85 kg; (b) MRI showing a herniated disc. 
Von Mises stresses are the highest in intervertebral discs and are concentrated in the disk D1, in contact with the L5 vertebra and the sacrum; Figure 20(a) clearly shows that the level of deformation of Von Mises is maximal in the disc D1, valued at $7.5063 \mathrm{~mm} / \mathrm{mm}$. This shows that the distance between the load application point and the axis of the spine has an important role in the increase of solicitation of this one and therefore of its deformation (Figure 20(b)).

\section{Acknowledgements}

The authors extend their appreciation to the Director of Scientific Research at LaBPS for funding the work through the Biomechanics Research Group.

\section{References}

[1] Grillo, G., Koca, O., Eskitascioglu, G. and Usumez, A. (2005) Three Dimensional Finite Element Analysis of Functional Stresses in Different Bone Locations Produced by Implants Placed in the Maxillary Posterior Region of the Sinus Floor. Journal of Prosthetic Dentistry, 93, 38-44. http://dx.doi.org/10.1016/j.prosdent.2004.10.001

[2] Brunski, J.B. (1997) Biomechanics of Dental Implants. In: Block, M., Kent, J.N. and Guerra, L.R., Eds., Implants in Dentistry, W.B. Saunders, Philadelphia, 63-71.

[3] Thomas, M. (2008) Contribution a l'analyse biomecanique et a l'evaluation des implants rachidiens. L'école nationale superieure d'arts et metiers specialite "biomecanique", Paris.

[4] Dr Kassab, M. Centre Avicenne Médical, 2 Av Tahar Sfar, 2092, El Manar 2, Tunis.

[5] Dietrich, M., Kedzior, K., Borkowski, P., Krzesinski, G., Skalski, K. and Zagrajek, T. (2005) A Nonlinear Analysis of the Human Vertebral Column and Medical Recommendations That Follow. Bulletin of the Polish Academy of Sciences, Technical Sciences, 53, 179-194.

[6] White Iii, A.A. and Panjabi, M.M. (1990) Clinical Biomechanics of the Spine.

[7] Marcovschi Champain, S. (2008) Corrélations Entre Les Paramètres Biomécaniques Du Rachis Et Les Indices Cliniques Pour L’analyse Quantitative Des Pathologies Du Rachis Lombaire Et De Leur Traitement Chirurgical, Enam, Paris.

[8] Starmans, F.J., Steen, W.H. and Bosman, F. (1993) A Three-Dimensional, Finite-Element Analysis of Bone Around Dental Implants in an Edentulous Human Mandible. Archives of Oral Biology, 38, 491-496. http://dx.doi.org/10.1016/0003-9969(93)90185-O

[9] Pr. Francois, L. (1997) Biomécanique Et Ostéosynthèse Du Rachis Ensm-Lbm Conférences D’enseignement De La Sofcot.

[10] Ibarz, E., Más, Y., Mateo, J., Lobo-Escolar, A., Herrera, A. and Gracia, L. (2013) Instability of the Lumbar Spine Due to Disc Degeneration. A Finite Element Simulation. Advances in Bioscience and Biotechnology, 4, 548-556. http://dx.doi.org/10.4236/abb.2013.44072

[11] Song, M., Zhang, Z., Lu, M., Zong, J., Dong, C., Ma, K. and Wang, S. (2014) Four Lateral Mass Screw Fixation Techniques in Lower Cervical Spine Following Laminectomy: A Finite Element Analysis Study of Stress Distribution. Biomedical Engineering Online, 13, 115. http://dx.doi.org/10.1186/1475-925X-13-115

[12] Rundell, S.A., Isaza, J.E. and Kurtz, S.M. (2011) Biomechanical Evaluation of a Spherical Lumbar Interbody Device at Varying Levels of Subsidence. SAS Journal, 5, 16-25.

[13] Goel, V.K., Mehta, A., Jangra, J., Faizan, A., Kiapour, A., Hoy, R.W. and Fauth, A.R. (2007) Anatomic Facet Replacement System (AFRS) Restoration of Lumbar Segment Mechanics to Intact: A Finite Element Study and in Vitro Cadaver Investigation. SAS Journal, 1, 46-54. http://dx.doi.org/10.1016/S1935-9810(07)70046-4

[14] Holekamp, S., Goel, V., Kuroki, H., Huntzinger, J. and Ebraheim, N. (2007) Optimal Intervertebral Sealant Properties for the Lumbar Spinal Disc: A Finite-Element Study. SAS Journal, 1, 68-73. http://dx.doi.org/10.1016/s1935-9810(07)70049-X

[15] Castellvi, A.E., Huang, H., Vestgaarden, T., Saigal, S., Clabeaux, D.H. and Pienkowski, D. (2007) Stress Reduction in Adjacent Level Discs via Dynamic Instrumentation: A Finite Element Analysis. SAS Journal, 1, 74-81. http://dx.doi.org/10.1016/S1935-9810(07)70050-6

[16] López, E., Ibarz, E., Herrera, A., Mateo, J., Lobo-Escolar, A., Puértolas, S. and Gracia, L. (2014) Probability of Osteoporotic Vertebral Fractures Assessment Based on DXA Measurements and Finite Element Simulation. Advances in Bioscience and Biotechnology, 5, 527-545. http://dx.doi.org/10.4236/abb.2014.56063

[17] Kiapour, A., Kiapour, A.M., Kodigudla, M., Hill, G.M., Mishra, S. and Goel, V.K. (2012) A Biomechanical Finite Element Study of Subsidence and Migration Tendencies in Stand-Alone Fusion Procedures_Comparison of an in Situ 
Expandable Device with a Rigid Device. Journal of Spine, 1, 4.

[18] Zheng, S.-N., Yao, Q.-Q., Wang, L.-M., Hu, W.-H., Wei, B., Xu, Y. and Zhang, D.-G. (2013) Biomechanical Effects of Semi-Constrained Integrated Artificial Discs on Zygapophysial Joints of Implanted Lumbar Segments. Experimental and Therapeutic Medicine, 6, 1423-1430.

[19] Byun, D.-H., Ah Shin, D., Kim, J.-M., Kim, S.-H. and Kim, H.-I. (2012) Finite Element Analysis of the Biomechanical Effect of Coflex ${ }^{\mathrm{TM}}$ on the Lumbar Spine, Laboratory Investigation. Korean Journal of Spine, 9, 131-136. http://dx.doi.org/10.14245/kjs.2012.9.3.131

[20] Lan, C.-C., Kuo, C.-S., Chen, C.-H. and Hu, H.-T. (2013) Finite Element Analysis of Biomechanical Behavior of Whole Thoraco-Lumbar Spine with Ligamentous Effect. The Changhua Journal of Medicine, 11, 26-41.

[21] Natarajan, R.N. and Andersson, G.B.J. (1997) Modeling the Annular Incision in a Herniated Lumbar Intervertebral Disc to Study Its Effect on Disc Stability. Computers \& Structures, 64, 1291-1297. http://dx.doi.org/10.1016/S0045-7949(97)00023-0

[22] Pitzen, T., Geisler, F.H., Matthis, D., Storz, H.M., Pedersen, K. and Steudel, W.I. (2001) The Influence of Cancellous Bone Density on Load Sharing in Human Lumbar Spine: A Comparison between an Intact and a Surgically Altered Motion Segment. European Spine Journal, 10, 23-29. http://dx.doi.org/10.1007/s005860000223

[23] Polikeit, A. (2002) Finite Element Analysis of the Lumbar Spine: Clinical Application. Inaugural Dissertation, University of Bern, Bern.

[24] Denoziere, G. (2004) Numerical Modeling of a Ligamentous Lumber Motion Segment. Master’s Thesis, Department of Mechanical Engineering, Georgia Institute of Technology, Georgia.

[25] Gwanseob, S. (2005) Viscoelastic Responses of the Lumbar Spine during Prolonged Stooping. PhD Dissertation, North Carolina State University, Raleigh.

[26] Sairyo, K., Goel, V.K., Masuda, A., Vishnubhotla, S., Faizan, A., Biyani, A., Ebraheim, N., Yonekura, D., Murakami, R.I. and Terai, T. (2006) Three-Dimensional Finite Element Analysis of the Pediatric Lumbar Spine. European Spine Journal, 15, 923-929. http://dx.doi.org/10.1007/s00586-005-1026-z

[27] Rohlmann, A., Burra, N.K., Zander, T. and Bergmann, G. (2007) Comparison of the Effects of Bilateral Posterior Dynamic and Rigid Fixation Devices on the Loads in the Lumbar Spine: A Finite Element Analysis. European Spine Journal, 16, 1223-1231. http://dx.doi.org/10.1007/s00586-006-0292-8

[28] Wilke, H.J., Neef, P., Caimi, M., Hoogland, T. and Claes, L.E. (1999) New in Vivo Measurements of Pressures in the Intervertebral Disc in Daily Life. Spine, 24, 755-762. http://dx.doi.org/10.1097/00007632-199904150-00005

[29] Smit, T., Odgaard, A. and Schneider, E. (1997) Structure and Function of Vertebral Trabecular Bone. Spine, 22, 28232833. http://dx.doi.org/10.1097/00007632-199712150-00005

[30] Sharma, M., Langrana, N.A. and Rodriguez, J. (1995) Role of Ligaments and Facets in Lumbar Spinal Stability. Spine, 20, 887-900. http://dx.doi.org/10.1097/00007632-199504150-00003

[31] Lee, K. and Teo, E. (2004) Effects of Laminectomy and Facetectomy on the Stability of the Lumbar Motion Segment. Medical Engineering \& Physics, 26, 183-192. http://dx.doi.org/10.1016/j.medengphy.2003.11.006

[32] Rohlmann, A., Zander, T., Schmidt, H., Wilke, H.J. and Bergmann, G. (2006) Analysis of the Influence of Disc Degeneration on the Mechanical Behaviour of a Lumbar Motion Segment Using the Finite Element Method. Journal of Biomechanics, 39, 2484-2490. http://dx.doi.org/10.1016/j.jbiomech.2005.07.026

[33] Ng, H.W. and Teo, E.C. (2001) Nonlinear Finite-Element Analysis of the Lower Cervical Spine (C4-C6) under Axial Loading. Journal of Spinal Disorders, 14, 201-210. http://dx.doi.org/10.1097/00002517-200106000-00003

[34] Ng, H.-W., Teo, E.-C. and Zhang, Q.-H. (2004) Influence of Laminotomies and Laminectomies on Cervical Spine Biomechanics under Combined Flexion-Extension. Journal of Applied Biomechanics, 20, 243-259.

[35] Gong, Z.Q., Chen, Z.X., Feng, Z.Z., Cao, Y.W., Jiang, C. and Jiang X.X. (2014) Finite Element Analysis of 3 Posterior Fixation Techniques in the Lumbar Spine. Orthopedics, 37, E441-E448. http://dx.doi.org/10.3928/01477447-20140430-54

[36] Kim, H.-J., Kang, K.T., Chang, B.-S., Lee, C.-K., Kim, J.-W. and Yeom, J.-S. (2014) Biomechanical Analysis of Fusion Segment Rigidity upon Stress at Both the Fusion and Adjacent Segments: A Comparison between Unilateral and Bilateral Pedicle Screw Fixation. Yonsei Medical Journal, 55, 1386-1394. http://dx.doi.org/10.3349/ymj.2014.55.5.1386

[37] Goel, V.-K., Kiapour, A., Faizan, A., Krishna, M. and Friesem, T. (2006) Finite Element Study of Matched Paired Posterior Disc Implant and Dynamic Stabilizer (360 Motion Preservation System). SAS Journal, 1, 55-62. http://dx.doi.org/10.1016/S1935-9810(07)70047-6

[38] Tang, S. and Meng, X.Y. (2010) Does Disc Space Height of Fused Segment Affect Adjacent Degeneration in ALIF? A Finite Element Study. Journal of Turkish Neurosurgery, 3, 296-303. 
[39] Kim, K.-T., Lee, S.-H., Suk, K.-S., Lee, J.-H. and Jeong, B.-O. (2010) Biomechanical Changes of the Lumbar Segment after Total Disc Replacement: Charite ${ }^{\circledR}$, Prodisc ${ }^{\circledR}$ and Maverick ${ }^{\circledR}$ Using Finite Element Model Study. Journal of Korean Neurosurgical Society, 47, 446-453. http://dx.doi.org/10.3340/jkns.2010.47.6.446

[40] Agarwal, A., Agarwal, A.-K. and Goel, V.-K. (2013) The Endplate Morphology Changes with Change in Biomechanical Environment Following Discectomy. International Journal of Clinical Medicine, 4, 8-17. http://dx.doi.org/10.4236/ijcm.2013.47A1002

[41] Zhong, Z.-C., Wei, S.-H., Wang, J.-P., Feng, C.-K., Chen, C.-S. and Yu, C.-H. (2006) Finite Element Analysis of the Lumbar Spine with a New Cage Using a Topology Optimization Method. Medical Engineering \& Physics, 28, 90-98. http://dx.doi.org/10.1016/j.medengphy.2005.03.007

[42] Sairyo, K., Goel, V.-K., Masuda, A., Vishnubhotla, S., Faizan, A., Biyani, A., et al. (2006) Three Dimensional Finite Element Analysis of the Lumbar Spine. European Spine Journal, 15, 923-929.

[43] Goto, K., Tajima, N., Chosa, E., Totoribe, K., Kuroki, H., Arizumi, Y. and Arai, T. (2002) Mechanical Analysis of the Lumbar Vertebrae in a Three-Dimensional Finite Element Method Model in Which Intradiscal Pressure in the Nucleus Pulposus Was Used to Establish the Model. Journal of Orthopaedic Science, 7, 243-246.

http://dx.doi.org/10.1007/s007760200040 